\title{
In Vitro Evaluation of Antibacterial Properties of Zinc Oxide Nanoparticles alone and in Combination with Antibiotics against Avian Pathogenic E. coli
}

\author{
Mohamed Shakal ${ }^{1 *}$, Emad Salah ${ }^{2}$, Maha, A. Saudi ${ }^{1}$, Eman, A. Morsy ${ }^{3}$, Shaza Ahmed ${ }^{2}$ and Ayman Amin ${ }^{4}$ \\ ${ }^{1}$ Endemic and Emerging Poultry Diseases Research Center, Cairo University, Egypt \\ ${ }^{2}$ Faculty of Biotechnology, October University for Modern Sciences and Arts (MSA), Giza, Egypt \\ ${ }^{3}$ Department of poultry diseases, Faculty of Veterinary Medicine, Cairo University, Egypt \\ ${ }^{4}$ Department of Plant Physiology, Faculty of Agriculture, Cairo University Giza, Egypt, \\ ${ }^{*}$ Corresponding author's Email: shakal2000@ gmail.com; ORCID: 0000-0002-1625-7324
}

Received: 11 Feb. 2020

Accepted: 22 Mar. 2020

\begin{abstract}
Antibiotic-resistant bacteria have become one of the major issues and concerns worldwide. For the past years, scientists have investigated the use of treatments in the nano-scale. Nanomaterials, such as metal oxide nanoparticles, have shown promising results due to their antibacterial properties. The aim of this study was to investigate the efficiency of in vitro antibacterial activity of zinc oxide nanoparticles ( $\mathrm{ZnO} \mathrm{NPs}$ ) alone and in combination with different antibiotics against avian pathogenic Escherichia coli. In this study, ZnO NPs were synthesized using direct precipitation method. Physical characteristics of ZnO NPs were confirmed using X-ray diffraction and transmission electron microscopy. Antibacterial resistance pattern of 10 antibiotics including amoxicillin, ciprofloxacin, enrofloxacin, gentamicin, doxycycline, levofloxacin, trimethoprim/sulfamethoxazole, tetracycline, spiramycin, and streptomycin, in addition to different concentrations of ZnO NPs, was determined by disc diffusion method on 10 avian pathogenic E. coli (APEC). The results showed that $50 \%$ of the strains were resistant to all antibiotics, while the rest were found to be sensitive to one or two antibiotics. The best concentration of ZnO NPs was $50 \mathrm{mg} / \mathrm{disk}$, which showed greater zones than that of other used concentrations $(25,12.5,6.25,3.125$, and $1.56 \mathrm{mg} / \mathrm{disk})$. The combination of spiramycin and gentamycin with $\mathrm{ZnO}$ NPs showed a synergistic effect while the combination of $\mathrm{ZnO}$ NPs with ciprofloxacin, enrofloxacin, and streptomycin showed an antagonistic effect. No antibacterial effect was observed in combination of $\mathrm{ZnO}$ NPs with other used antibiotics. This study recommends in vivo evaluations to confirm the results.
\end{abstract}

Keywords: Antibiotic, Escherichia coli, Nanoparticle, Zinc Oxide

\section{INTRODUCTION}

Escherichia coli is a bacterial species identified as a normal inhabitant of the gastrointestinal tract of humans and animals. It is also a part of normal intestinal microflora in avian species (De Carli et al., 2015). Certain pathogenic strains of $E$. coli invade several organs of birds and causes localized or systemic infections, collectively named as colibacillosis (Matter et al., 2011 and De Carli et al., 2015) which, caused by Avian Pathogenic E. coli (APEC) (Matin et al., 2017). Colibacillosis is responsible for significant economic losses in the poultry industry globally (Ewers et al., 2003 and Raji et al., 2007). The escalation of colibacillosis in both the incidence and severity indicates that it is likely to continue and become an even larger problem in the poultry industry. However, the use of antimicrobial therapy is a key tool in decreasing the incidence and mortality of avian colibacillosis (Dheilly et al., 2012). Unfortunately, there are increasing numbers of $E$. coli strains that have become resistant to antibiotics. Antibiotic-resistant bacteria have become a global problem, which has been threatening public health in the last few years. To overcome this problem, nanomaterials, such as metal oxide nanoparticles, have appeared as promising candidates. Nanoparticles are a distinctive group of materials with unique structures and a wide range of applications in various disciplines (Matei et al., 2008). Furthermore, nanotechnology has considerably progressed due to its vast applications and uses (Suresh et al., 2016).

Zinc oxide nanoparticles ( $\mathrm{ZnO} \mathrm{NPs}$ ) signify a significant class of commercially sustainable products. $\mathrm{ZnO}$ NPs have several characteristics that allow it to have 
numerous advantages in their use. One of their major uses is being an antimicrobial agent due to their high efficiency on resistant strains of microbial pathogens, reduced toxicity and heat resistant properties (Jin et al., 2009; Rizwan et al., 2010). Additionally, ZnO NPs have other significant features such as physical and chemical stability, high catalysis activity as well as intensive ultraviolet and infrared adsorption with a wide range of applications as semiconductors, sensors, transparent electrodes (Matei et al., 2008; Kalyani et al., 2006). Moreover, $\mathrm{ZnO}$ has received substantial attention in recent years because of its distinctive magnetic, optical, and piezoelectric properties (Marcus and Paul, 2007). For these reasons, the present study aimed to examine the antibacterial effect of different $\mathrm{ZnO}$ NPs concentrations on $E$. coli different serotypes as well as examine the effect of the combination between antibiotic and ZnO NPs on $E$. coli antibacterial sensitivity.

\section{MATERIALS AND METHODS}

The study was carried out in Endemic and Emerging Poultry Diseases Research Center, Cairo University, Sheikh Zayed, $6^{\text {th }}$ of October, Giza, Egypt throughout the last half of 2019.

\section{Preparation of zinc oxide nanoparticles}

Zinc Oxide Nanoparticles ( $\mathrm{ZnO}$ NPs) were synthesized by direct precipitation, using zinc nitrate and $\mathrm{KOH}$ as precursors. In this work, the aqueous solution $(0.2 \mathrm{M})$ of zinc nitrate $\left(\mathrm{Zn}\left(\mathrm{NO}_{3}\right)_{2} \cdot 6 \mathrm{H}_{2} \mathrm{O}\right)$ and the solution $(0.4 \mathrm{M})$ of $\mathrm{KOH}$ were prepared with deionized water, respectively. The $\mathrm{KOH}$ solution was slowly added into zinc nitrate solution at room temperature under vigorous stirring, which resulted in the formation of a white suspension. The white product was centrifuged at 5000 rpm for $20 \mathrm{~min}$ and washed 3 times with distilled water and washed with absolute alcohol at last. The obtained product was calcined at $500{ }^{\circ} \mathrm{C}$ in air atmosphere for $3 \mathrm{hr}$.

\section{Characterization of zinc oxide nanoparticles}

To confirm the physical characteristics of ZnO NPs, the following techniques were performed: X-Ray Diffraction (XRD) and Transmission Electron Microscopy (TEM) XRD was performed at Central laboratory, Tanta University. TEM was performed in the National Research Center, Giza, Egypt.

\section{X-Ray Diffraction analysis}

$\mathrm{X}$-ray diffraction was carried using Rigaku X-ray diffractometer system over $20<2 \theta<80$ using $\mathrm{Cu}-\mathrm{K} \alpha$ radiation of wavelength $\lambda=0.154 \mathrm{~nm}$.

\section{Transmission Electron Microscope}

Transmission electron microscope was used for further structural characterization. A small amount of $\mathrm{ZnO}$ NPs was dispersed in alcohol by ultra-sonication. A drop of the previous solution was taken on a carbon-coated grid for TEM imaging.

\section{Bacterial Strain}

Ten E. coli isolates (previously isolated from broiler chicks suffered from high mortalities). (Khelfa and Morsy 2015). These isolates are E. coli $\mathrm{O}_{6}, \mathrm{O}_{26}, \mathrm{O}_{27}, \mathrm{O}_{78}, \mathrm{O}_{114}$, $\mathrm{O}_{119}, \mathrm{O}_{142}, \mathrm{O}_{158}$, and $\mathrm{O}_{159}$. All serotypes were grown aerobically in nutrient broth at $37^{\circ} \mathrm{C}$ for $24 \mathrm{~h}$ before using as target organisms. The density of bacterial isolates was adjusted to an optical density of $0.5 \mathrm{McF}$ arland standards.

\section{Antimicrobial sensitivity test}

Antibiotic sensitivity test of the E. coli isolates was tested against 10 antibiotic disks from (Oxoid, Hampshire, UK): amoxicillin (AMC, $10 \mu \mathrm{g}$ ), ciprofloxacin (CIP, 5 $\mu \mathrm{g}$ ), enrofloxacin (EX, $5 \mu \mathrm{g}$ ), gentamicin (CN, $10 \mu \mathrm{g}$ ), doxycycline (Do, $30 \mu \mathrm{g}$ ), levofloxacin (LEV, $5 \mu \mathrm{g}$ ), trimethoprim/sulfamethoxazole (SXT, 1.25/23.75 $\mu \mathrm{g}$ ), tetracycline (TE, $30 \mu \mathrm{g}$ ), spiramycin (SR, $100 \mu \mathrm{g}$ ) and streptomycin $(\mathrm{S}, 10 \mu \mathrm{g})$. These antibiotics were selected due to their extensive consumption in the poultry feed for treatment of colibacillosis and other avian diseases. The test performed following a modified Kirby-bauer disk diffusion method as recommended by the Clinical and Laboratory Standards Institute (CLSI, 2014).

To examine the antibacterial activity of the $\mathrm{ZnO}$ nanoparticles on the E. coli microorganisms, $\mathrm{ZnO}$ nanoparticles were suspended in sterile normal saline and constantly stirring until a uniform colloidal suspension was formed to yield a powder concentration of 1000 $\mathrm{mg} / \mathrm{ml}$. Two-fold serial dilution was made and the first 5 concentrations were tested. $0.05 \mathrm{ml}$ of various concentrations of $\mathrm{ZnO}$ nanoparticle was added in discs. After the inoculation and cultivation of $E$. coli on top of nutrient agar, discs were placed in selected areas on different plates. The zone of inhibition (ZOI) was measured after $24 \mathrm{~h}$ incubation. The antibacterial activity of $\mathrm{ZnO}$ NPs alone and with antibiotics was compared. 


\section{RESULTS}

Different techniques were used to characterize the synthesized $\mathrm{ZnO}$ NPs. Crystal structure and primary crystal size were characterized using XRD. Other than that, the morphological features especially the size and the shape of $\mathrm{ZnO}$ NPs were determined using Transmission Electron Microscope (TEM).

The XRD represented in Figure 1 showed broad diffraction peaks at $2 \theta$ values $31.70,34.37,36.19,56.51$ and 62.78 which are typical for the $\mathrm{ZnO}$ structure. Notable line broadening of diffraction peaks is an indication that the synthesized materials are in the nanometer range (Reference code. 96-900-4180). Furthermore, TEM images of $\mathrm{ZnO}$ confirmed that the particles are almost hexagonal. The average particle size was found to be 25 $32 \mathrm{~nm}$ (Figure 2) reveals that most of the ZnO NPs are hexagonal in shape with average particles of the size 28.

Antibiotic sensitivity test showed E. coli resistance against all tested antibiotics except E. coli O6, O44 and
O119 were sensitive to gentamycin, E. coli O27 and O 159 were sensitive to tetracycline, while $\mathrm{O} 26$ and $\mathrm{O} 44$ were sensitive to ciprofloxacin and levofloxacin, respectively as represented in table 1. The antibacterial effect of $\mathrm{ZnO}$ NPs showed that the concentration contributed to greater ZOI was $50 \mathrm{mg} /$ disk, the zone is decreased in size as the concentration of $\mathrm{ZnO}$ NPs decreased until no ZOI at 1.56 $\mathrm{mg} / \mathrm{disk}$ was detected as represented in table 2 . The combination of $\mathrm{ZnO}$ NPs concentration that contributed to a broader zone $(50 \mathrm{mg})$ and antibiotics showed different results between the different antibiotics; that is, there was a synergistic effect between $\mathrm{ZnO} \mathrm{NPs}$ and gentamycin which gave ZOI of 22.1, while ZnO NPs alone gave ZOI of 19.8. Similarly, spiramycin gave ZOI of 21.5 in combination with $\mathrm{ZnO}$ NPs. In contrast, the combination with ciprofloxacin, streptomycin, and enrofloxacin gave ZOI of 15.6, 15.2 and 13.4, respectively which were less than that of $\mathrm{ZnO}$ NPs alone and that may indicate the antagonistic effect between those antibiotic types and $\mathrm{ZnO}$ NPs as represented in table 3 .

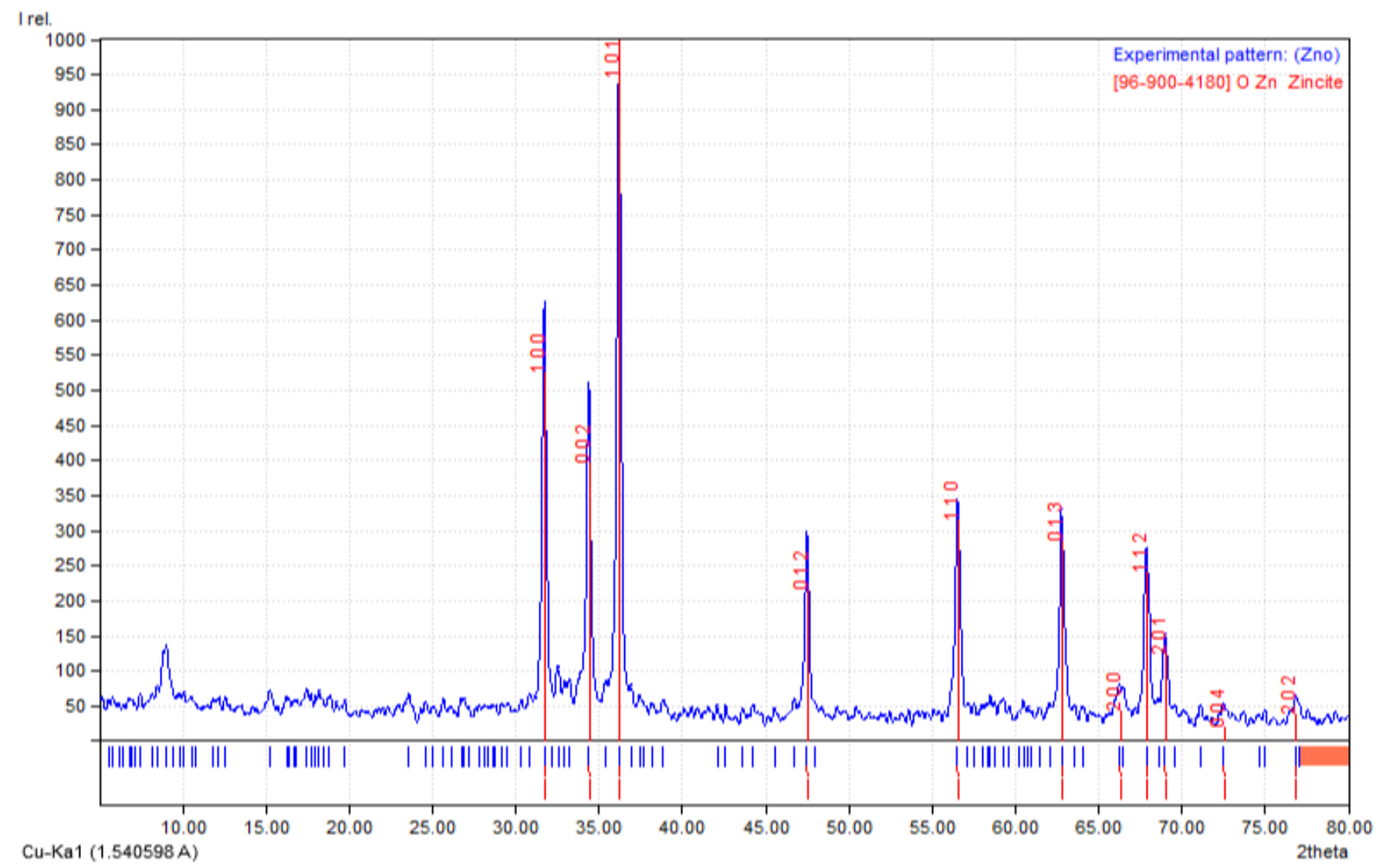

Figure 1. X-ray diffraction pattern of synthesized zinc oxide nanoparticles 

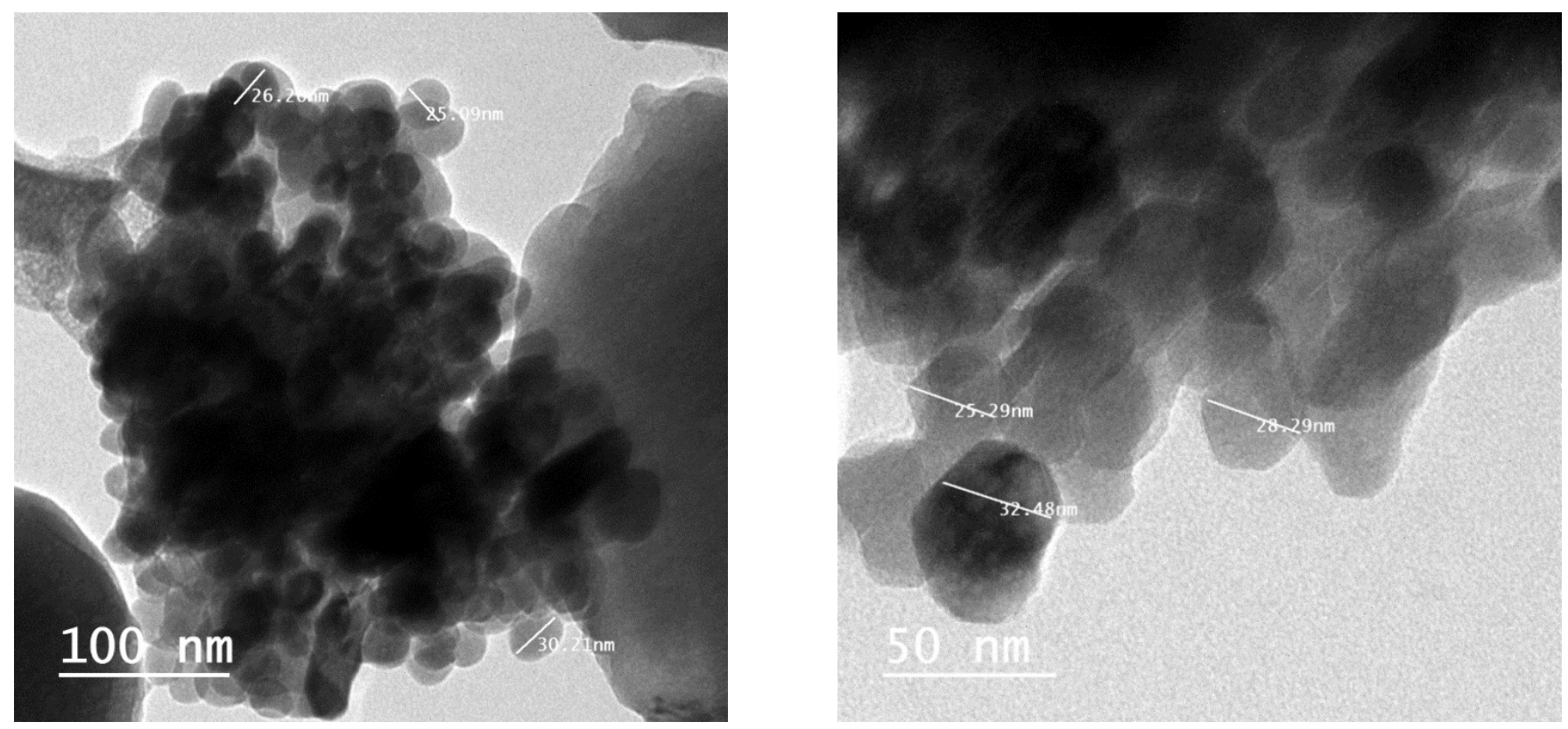

Figure 2. Transmission Electron Microscopy image of synthesized zinc oxide nanoparticles

Table 1. Results of antibiotic sensitivity test for Escherichia coli serotypes

\begin{tabular}{|c|c|c|c|c|c|c|c|c|c|c|c|c|}
\hline Strain & Antibacterial agent & AML & CIP & $\mathbf{E x}$ & Cn & Do & LEV & SXT & SR & $\mathbf{T E}$ & $\mathbf{S}$ & $\begin{array}{l}\text { Sensitivity } \\
\text { percentage }\end{array}$ \\
\hline E. coli $\mathrm{O}_{158}$ & & $\mathrm{r}$ & $\mathrm{r}$ & $\mathrm{r}$ & $\mathrm{r}$ & $\mathrm{r}$ & $\mathrm{r}$ & $\mathrm{r}$ & $\mathrm{r}$ & $\mathrm{r}$ & $\mathrm{r}$ & $0 \%$ \\
\hline E. coli $\mathrm{O}_{78}$ & & $\mathrm{r}$ & $\mathrm{r}$ & $\mathrm{r}$ & $\mathrm{r}$ & $\mathrm{r}$ & $r$ & $r$ & $\mathrm{r}$ & $r$ & $\mathrm{r}$ & $0 \%$ \\
\hline E. coli $\mathrm{O}_{114}$ & & $\mathrm{r}$ & $\mathrm{i}$ & $\mathrm{i}$ & $\mathrm{r}$ & $\mathrm{r}$ & $\mathrm{r}$ & $\mathrm{r}$ & $\mathrm{r}$ & $\mathrm{r}$ & $\mathrm{r}$ & $0 \%$ \\
\hline E. coli $\mathrm{O}_{44}$ & & $\mathrm{r}$ & $\mathrm{r}$ & $\mathrm{r}$ & s & $\mathrm{r}$ & $\mathrm{s}$ & $\mathrm{r}$ & $\mathrm{r}$ & $\mathrm{r}$ & $\mathrm{r}$ & $20 \%$ \\
\hline E. coli $\mathrm{O}_{26}$ & & $\mathrm{r}$ & $\mathrm{s}$ & $\mathrm{i}$ & $\mathrm{i}$ & $\mathrm{r}$ & $\mathrm{r}$ & $\mathrm{r}$ & $\mathrm{r}$ & $\mathrm{r}$ & $\mathrm{r}$ & $10 \%$ \\
\hline E. coli $\mathrm{O}_{119}$ & & $\mathrm{r}$ & $\mathrm{i}$ & $\mathrm{r}$ & s & $\mathrm{r}$ & $\mathrm{r}$ & $\mathrm{r}$ & $\mathrm{r}$ & $\mathrm{r}$ & $\mathrm{r}$ & $10 \%$ \\
\hline E. coli $\mathrm{O}_{55}$ & & $\mathrm{r}$ & $\mathrm{r}$ & $\mathrm{r}$ & $\mathrm{r}$ & $\mathrm{r}$ & $\mathrm{r}$ & $\mathrm{r}$ & $\mathrm{r}$ & $\mathrm{r}$ & $\mathrm{r}$ & $0 \%$ \\
\hline E. coli $\mathrm{O}_{159}$ & & $\mathrm{r}$ & $\mathrm{r}$ & $\mathrm{r}$ & $\mathrm{r}$ & $\mathrm{r}$ & $\mathrm{r}$ & $\mathrm{r}$ & $\mathrm{r}$ & s & $\mathrm{r}$ & $10 \%$ \\
\hline E. coli $\mathrm{O}_{27}$ & & $\mathrm{r}$ & $\mathrm{r}$ & $r$ & $\mathrm{i}$ & $\mathrm{r}$ & $r$ & $\mathrm{r}$ & $\mathrm{r}$ & s & $\mathrm{r}$ & $10 \%$ \\
\hline E. coli $\mathrm{O}_{6}$ & & $\mathrm{r}$ & $\mathrm{r}$ & $\mathrm{r}$ & $\mathrm{s}$ & $\mathrm{r}$ & $\mathrm{r}$ & $\mathrm{r}$ & $\mathrm{i}$ & $\mathrm{r}$ & $\mathrm{r}$ & $10 \%$ \\
\hline
\end{tabular}

$\mathrm{i}=$ intermediate; $\mathrm{r}=$ resistance; $\mathrm{s}=$ sensitive AML: amoxicillin, CIP: ciprofloxacin, Ex: enrofloxacin, Cn: gentamicin, Do: doxycycline, LEV: levofloxacin, SXT: trimethoprim/sulfamethoxazole, SR: spiramycin, TE: tetracycline, S: streptomycin

Table 2. Zone of inhibition produced by different concentrations of zinc oxide nanoparticles for Escherichia coli serotypes

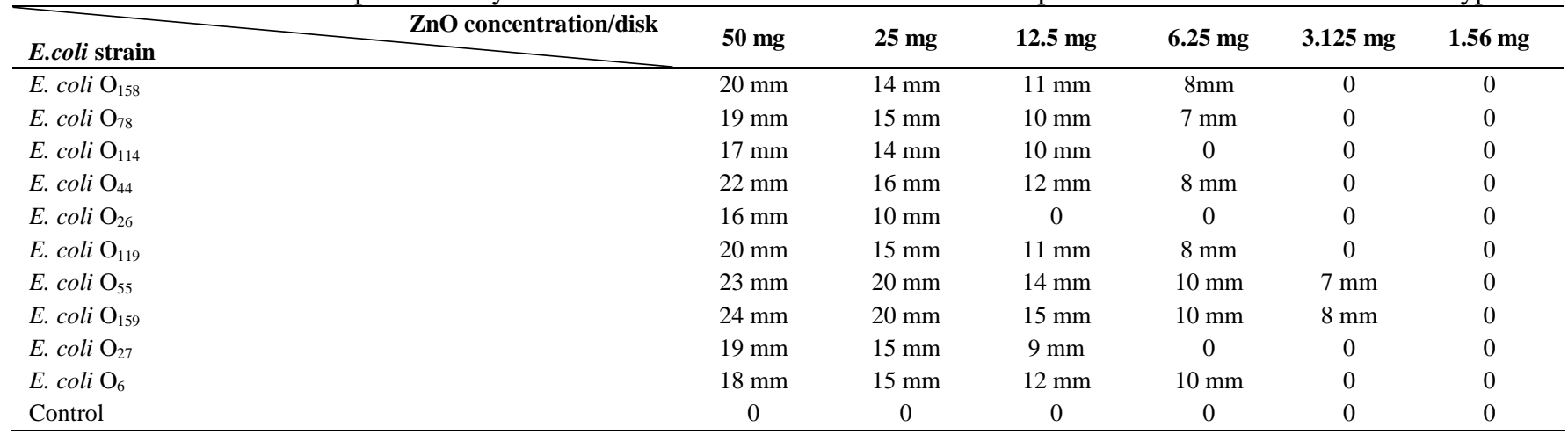

ZnO: zinc oxide 
Table 3. Zone of inhibition $(\mathrm{mm})$ of combination of zinc oxide nanoparticles $(50 \mathrm{mg} / \mathrm{disk})$ with different antibiotics for Escherichia coli serotypes

\begin{tabular}{|c|c|c|c|c|c|c|c|c|c|c|c|}
\hline Strain & $\begin{array}{l}\mathrm{ZnO} \\
\text { NPs }\end{array}$ & $\begin{array}{c}\text { AMC+ } \\
\text { ZnO } \\
\text { NPs } \\
\end{array}$ & $\begin{array}{l}\mathrm{CIP}+ \\
\mathrm{ZnO} \\
\mathrm{NPs} \\
\end{array}$ & $\begin{array}{l}\text { EX+ } \\
\text { ZnO } \\
\text { NPs } \\
\end{array}$ & $\begin{array}{l}\mathrm{CN}+ \\
\mathrm{ZnO} \\
\mathrm{NPs} \\
\end{array}$ & $\begin{array}{l}\text { DO+ } \\
\text { ZnO } \\
\text { NPs } \\
\end{array}$ & $\begin{array}{c}\text { LEV+ } \\
\text { ZnO } \\
\text { NPs } \\
\end{array}$ & $\begin{array}{c}\text { SXT+ } \\
\text { ZnO } \\
\text { NPs } \\
\end{array}$ & $\begin{array}{l}\text { SR+ } \\
\text { ZnO } \\
\text { NPs } \\
\end{array}$ & $\begin{array}{l}\text { TE+ } \\
\text { ZnO } \\
\text { NPs } \\
\end{array}$ & $\begin{array}{c}\text { S+ } \\
\text { ZnO } \\
\text { NPs } \\
\end{array}$ \\
\hline E. coli $\mathrm{O}_{158}$ & 20 & 18 & 16 & 13 & 24 & 19 & 19 & 18 & 23 & 19 & 15 \\
\hline E. coli $\mathrm{O}_{114}$ & 17 & 17 & 15 & 14 & 19 & 16 & 15 & 19 & 20 & 16 & 12 \\
\hline E. coli $\mathrm{O}_{44}$ & 22 & 21 & 17 & 16 & 23 & 22 & 21 & 20 & 20 & 20 & 18 \\
\hline E. coli $\mathrm{O}_{55}$ & 23 & 22 & 20 & 17 & 24 & 21 & 20 & 22 & 24 & 21 & 18 \\
\hline E. coli $\mathrm{O}_{159}$ & 24 & 23 & 19 & 18 & 22 & 23 & 24 & 23 & 23 & 23 & 16 \\
\hline E. coli $\mathrm{O}_{27}$ & 19 & 19 & 14 & 12 & 23 & 20 & 20 & 19 & 22 & 17 & 15 \\
\hline E. coli $\mathrm{O}_{6}$ & 18 & 18 & 13 & 11 & 22 & 17 & 19 & 16 & 19 & 17 & 13 \\
\hline
\end{tabular}

\section{DISCUSSION}

The present study demonstrated the potential of using $\mathrm{ZnO}$ NPs as an antibacterial agent as well as their efficiency to develop a synergistic effect with antibiotics. The employed methodology of the $\mathrm{ZnO} \mathrm{NP}$ production was based on structural and compositional characterization; the in situ produced $\mathrm{ZnO}$ NPs were interpreted using electron microscopy and XRD analysis.

The selected 10 types of antibiotics were used in combination with $\mathrm{ZnO}$ NPs against 10 strains of avian $E$. coli in order to inhibit its growth. The sensitivity test was performed primarily as control by using the antibiotics alone without the nanoparticles. The use of gentamicin showed that all the bacterial strains have resistance against this type of antibiotic except O6, O44, and O119; these three strains of $E$. coli were sensitive to gentamicin. All bacterial strains were resistant against tetracycline except $\mathrm{O} 27$ and $\mathrm{O} 159$. While $\mathrm{O} 26$ and $\mathrm{O} 44$ were sensitive to ciprofloxacin and levofloxacin. The results are in agreement with findings of a study conducted by Kibret and Abera (2011) who explained the antimicrobial sensitivity patterns of $E$. coli from human samples against the selected antibiotics used in the present study and reported high resistance rates to amoxicillin and tetracycline. In addition, gentamicin and ciprofloxacin produced high ZOI.

The experiment was followed by using the $\mathrm{ZnO}$ NPs with different concentrations as an antibacterial agent. Resistant strains were used to evaluate the effect of $\mathrm{ZnO}$
NPs. The results showed a prominent increase in the inhibition zone, starting with the concentration of 50 $\mathrm{mg}$ /disk, the inhibition zone was observed in all the bacterial strains at this concentration but in different sizes. The concentration of $25 \mathrm{mg} /$ disk showed an inhibition zone in all the E. coli strains. At the concentration of 12.5 $\mathrm{mg} / \mathrm{disk}$, the inhibition zone was observed in all types of bacterial strains except $\mathrm{O} 26$. The results indicated the ability of $\mathrm{ZnO} \mathrm{NPs}$ to inhibit E.coli through its antibacterial property.

In the concentration of $6.25 \mathrm{mg} / \mathrm{disk}$, the number of resistant strains was three. No inhibition zone was detected in concentrations of $3.125 \mathrm{mg} / \mathrm{disk}$ and $1.56 \mathrm{mg} / \mathrm{disk}$. The results showed that $\mathrm{ZnO}$ NPs $(50 \mathrm{mg} /$ disk, $25 \mathrm{mg} /$ disk, and $12 \mathrm{mg} /$ disk) enhanced antibacterial effects while lower concentrations had low or no effect.

The obtained results in the present study are supported by another research conducted by Rauf et al. (2017) who stated that $\mathrm{ZnO}$ NPs possess effective antibacterial activity against $E$. coli. The $\mathrm{ZnO}$ NPs antibacterial effect has been associated with bacterial exterior membranes decomposition by reactive oxygen species (ROS), mainly by the hydroxyl radicals $(\mathrm{OH})$, which lead to phospholipid peroxidation and eventually kill bacteria. Rauf et al. (2017) stated that nanoparticles have a physical property that allows them to adhere to a cell and kill the bacteria if they come in contact with it.

Another similar research conducted by Rizwan et al. (2010) stated that increasing the concentration of $\mathrm{ZnO}$ NPs increases the antibacterial activity. The inhibition zone 
size was divergent according to bacterial strain, size, and $\mathrm{ZnO}$ NPs concentration. Colonies' number forming unit (cfu) of E. coli and S. aureus were incubated overnight with different concentrations of ZnO NPs. The least concentration of $\mathrm{ZnO}$ NPs that inhibited the growth of bacteria was $3.1 \mathrm{mg} / \mathrm{ml}$ for $E$. coli and $1.5 \mathrm{mg} / \mathrm{ml}$ for S.aureus. The current study validates earlier researches and proposes that $\mathrm{ZnO}$ NPs in high concentrations have an antibacterial effect against resistant strains of $E$. coli.

The experiment followed was the evaluation of the effect of $\mathrm{ZnO}$ NPs with the antibiotics. The results indicated the ability of $\mathrm{ZnO}$ NPs' effect with 10 studied antibiotics as presented in table 3 . The results showed that the average size of inhibition zone caused by $\mathrm{ZnO}$ NPs was $19.8 \mathrm{~mm}$. When combining different antibiotics with $\mathrm{ZnO}$ NPs, gentamicin and $\mathrm{ZnO}$ NPs in concentration of $50 \mathrm{mg}$ resulted in the size of inhibition zone to be increased to $22.1 \mathrm{~mm}$; while using a combination of Spiramycin and $\mathrm{ZnO}$ NPs led to an inhibition zone of $21.5 \mathrm{~mm}$, which indicates a synergistic effect between $\mathrm{ZnO}$ NPs and (gentamicin and spiramycin). These two antibiotics with $\mathrm{ZnO}$ NPs have a prominent effect in inhibiting avian $E$. coli.

The other types of antibiotic such as ciprofloxacin, streptomycin, and enrofloxacin resulted in $15.6 \mathrm{~mm}, 15.2$ $\mathrm{mm}$, and $13.4 \mathrm{~mm}$ of the inhibition zone, respectively. The previous inhibition zones were smaller than the size of inhibition zone of $\mathrm{ZnO}$ NPs alone, so the combinations were not effective compared to the effect of ZnO NPs with gentamicin and spiramycin. This result could be explained by Rauf et al. (2017) who proposed combination of $\mathrm{ZnO}$ NPs with different antibiotics could using the disc diffusion method results could differ in efficiency due to the variances in fold increase among these antibiotics as well as their variance in their mechanism of action.

Another study conducted by Reddy et al. (2007), proposed that the higher susceptibility of Gram-positive bacteria can be related to differences in cell wall structure, cell physiology, metabolism or degree of contact. The results of time-dependent antibacterial activity of $\mathrm{ZnO}$ NPs indicated that CFU of the tested bacteria for each concentration declined gradually during $72 \mathrm{~h}$, whereas colony formation of control solution stayed uncountable. The antibacterial efficacy increased with decreasing particle size from bulk $\mathrm{ZnO}$ to white $\mathrm{ZnO}$ nanoparticles. Particle concentration seems to be more effective on the inhibition of bacterial growth than particle size under the condition of this work. The enhanced bioactivity of smaller particles probably is attributed to the higher surface area to volume ratio. $\mathrm{ZnO}$ NPs are effective antibacterial on Gram-negative bacteria. The same results were confirmed in the study of Zhongbing et al. (2008) in which Gram-negative membrane and Gram-positive membrane disorganization was approved by transmission electron microscopy of bacteria ultrathin sections.

In addition, Nazoori and Kariminik (2018) stated that antibacterial activity of $\mathrm{ZnO}$ NPs showed notable decreasing activity. The inhibition of growth was observed in a concentration-dependent manner for all bacteria which were statistically significant inhibitory effects compared with the control (general antibiotics) in this condition. Further studies should be performed investigating the toxic effect of ZnO NPs on bacteria.

\section{CONCLUSION}

The present study demonstrated the antibacterial activity of the addition of $\mathrm{ZnO}$ NPs to some antibiotics. The result showed a synergistic and antagonistic effect between $\mathrm{ZnO}$ NPs and some antibiotics on different avian E.coli strains. In conclusion, the study showed promising results to eradicate the issue of antibiotic resistance. This study recommends in vivo studies to confirm the obtained results.

\section{REFERENCES}

Clinical Laboratory Standards Institute (CLSI) (2014). Performance standards for antimicrobial susceptibility testing; 24th informational supplement (M100S23). Wayne PA, USA: CLSI.

De Carli S, Ikuta N, Lehmann FK, da Silveira VP, de Melo Predebon G and Fonseca AS (2015). Virulence gene content in Escherichia coli isolates from poultry flocks with clinical signs of colibacillosis in Brazil. Poultry Science, 94:2635-2640.

Dheilly A, Devendec L, Mourand G, Bouder A, Jouy E and Kempf I (2012). Resistance gene transfer during treatments for experimental avian colibacillosis. Antimicrobial Agents Chemotherapy, 56(1): 189-196.

Elaheh SN and Ashraf K (2018). In vitro evaluation of antibacterial properties of zinc oxide nanoparticles on pathogenic prokaryotes. Journal of Applied Biotechnology, 5(4): 162-165.

Ewers C, Janssen T and Wieler LH (2003). Avian pathogenic E. coli (APEC): a review. Berl Muuch Tierarztl Wochenschr, 116: 381395.

Khelfa DG and Morsy EA (2015). Incidence and distribution of some aerobic bacterial agents associated with high chick mortality in some broiler flocks in Egypt. Middle East Journal of Applied Sciences, 5(2):383-394.

Kibret M and Abera B (2011). Antimicrobial susceptibility patterns of $E$. coli from clinical sources in northeast Ethiopia. African health $\begin{array}{lllll}\text { sciences, } & 11 \quad \text { (Suppl 1): } & \text { S40-S45. } & \text { DOI: }\end{array}$ http://dx.doi.org/10.4314/ahs.v11i3.70069

Matin MA, Islam MA, and Khatun MM (2017). Prevalence of colibacillosis in chickens in greater Mymensingh district of Bangladesh. Veterinary World, 10:29-33.

Matter LB, Barbieri NL, Nordhoff M, Ewers C, and Horn F (2011). Avian pathogenic Escherichia coli MT78 invades chicken 
Shakal et al., 2020

fibroblasts. Veterinary Microbiology, 148:51-59. DOI: https://doi.org/10.1016/j.vetmic.2010.08.006

Raji M, Adekeye J, Kwaga J, Bale J, and Henton M (2007). Serovars and biochemical characterization of Escherichia coli isolated from colibacillosis cases and dead-in-shell embryos in poultry in ZariaNigeria. Veterinarski Arhiv, 77(6): 495-505.

Rauf M, Owais M, Rajpoot R, Faraz A, Nazoora K and Zubai S (2017). Biomimetically synthesized $\mathrm{ZnO}$ nanoparticles attain potent antibacterial activity against less susceptible $S$. aureus skin infection in experimental animals. RSC Advances, 7: 3636136373.

Reddy KM, Kevin F, Jason B, Denise GW, Cory H and Alex P (2007). Selective toxicity of zinc oxide nanoparticles to prokaryotic and eukaryotic systems. Journal Applied Physics Letters, 90(21): 213902.DOI: https://doi.org/10.1063/1.2742324
Rizwan W, Amrita M, Soon-Il Y, Young-Soon K and Hyung-Shik S (2010). Antibacterial activity of $\mathrm{ZnO}$ nanoparticles prepared via nonhydrolytic solution route. Journal of Applied Microbial Biotechnology, 87(5): 1917-1925.

Sadat N and Kariminik A (2018). In Vitro evaluation of antibacterial properties of zinc oxide nanoparticles on pathogenic prokaryotes. Journal of Applied Biotechnology Reports, 5(4):162-165. DOI:https://dx.doi.org/10.29252/JABR.05.04.05

Suresh S, Karthikeyan S, Saravanan P and Jayamoorthy K (2016). Comparison of antibacterial and antifungal activities of 5-amino2 mercaptobenzimidazole and functionalized $\mathrm{NiO}$ nanoparticles. Karbala International Journal of Modern Science, 2(3):188-195. DOI: https://doi.org/10.1016/j.kijoms.2016.05.001 